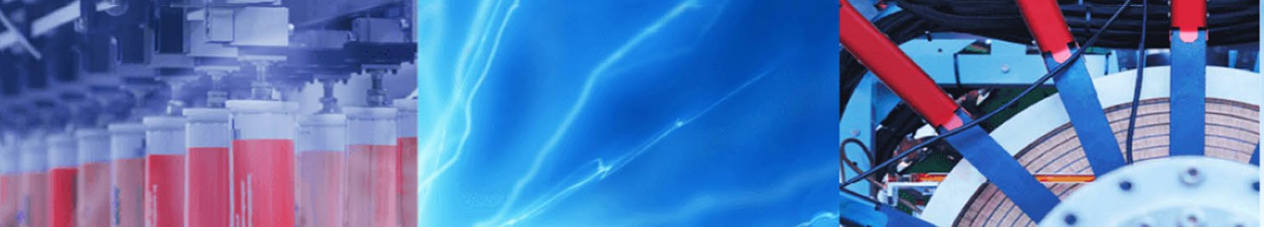

Review Paper

\title{
A review on multi sensor data fusion technique in CNC machining of tailor-made nanocomposites
}

\author{
K. V. V. N. R. Chandra Mouli ${ }^{1}$ Balla Srinivasa Prasad $^{2}$ (I) A. V. Sridhar ${ }^{1} \cdot$ Sandeep Alanka $^{2}$
}

Received: 15 October 2019 / Accepted: 10 April 2020 / Published online: 20 April 2020

(c) Springer Nature Switzerland AG 2020

\begin{abstract}
In this study, a multiple sensor data fusion system is anticipated as essential for monitoring of cutting operations, by identifying suitable sensor locations to obtain feedback signals periodically. The sensor signal derives the failure during machining owing to complex cutting tool geometry even in machining of composites. Nano metal matrix composites (NMMC) being extremely upright in mechanical characteristics, consequently machining of these hybrid nano metal matrix composites reinforced with difficult-to-cut nano particles leads to reduced tool life thereby causing rapid flank wear. Therefore, it is a challenge to identify the wear features caused during machining of tailor made NMMC's, reducing wastage and preventing machine malfunction. This paper presents a comprehensive review on the machining strategies in extreme output conditions which rely on input parameters of speed, feed and depth of cut influencing tool life during CNC machining. This can be achieved only with multiple sensor data fusion technique during CNC machining.
\end{abstract}

Keywords Multi-sensor data fusion · Sensors · CNC machining $\cdot$ Nanocomposites $\cdot$ Tool wear

\section{Introduction}

Due to the intense prerequisite of varied products and fall in the life of products, there is a crucial demand to increase the quality and quantity of manufacturing products. Where mandate consistent monitoring of machining is vital in reducing manufacturing cost in less time. The necessity of less dependency on the operator is essential in order to eradicate error and cost with less lead time, which will lead towards the automated machining till today. The automated machining process in which complex tool path stratagems with intense updated machining techniques such as high-speed milling, drilling turning are in demand. That becomes reasonable for getting complex geometric of the machined product, for instance, precise surface textures. The possession of materials having less finish which are by difficult-to-cut super alloys of titanium, lead to tool failure and wear during machining, forming typical wear features. Duro et al. [1] intimate from his study that, to prevent the occurrence of wastage in the machining of certain cost allied superalloy components, it is important to intensely find out the workpiece and machine tool malfunctions resulting damage of tool and product machined. The cause of tool damage in any interrupted machining process such as milling operation is mainly, by which tool enter into and exit out of the workpiece several times per second owing to varied chip thickness. This mechanism involves tool disclosed to several thermal and mechanical shocks resulting predominant lopsided tool wear. The rise in the necessity of observing the condition of the cutting tools and workpiece in any machining operation, lead a way to avoid unexpected machine malfunctions bringing out accuracy. Since the' $90 \mathrm{~s}$, monitoring of the condition of the cutting tool raised a boon in researchers and manufacturing velvets. From the studies of Yesilyurt et al. [2] the status of the cutting tool is assessed either by the method

Balla Srinivasa Prasad, bsp.prasad@gmail.com | ${ }^{1}$ Mechanical Engineering, GIT, GITAM Deemed To Be University, Visakhapatnam 530045, India. ${ }^{2}$ Department of Mechanical Engineering, GIT, GITAM Deemed To Be University, Visakhapatnam 530045, India. 
of measuring directly (by radioactive, chemical and optical apparatus) or indirectly (through measuring parameters such as torque, forces, feed, sound, spindle motor currents, spindle speed, doc, vibration, acoustic emissions, cutting temperature). However, measuring these parameters to estimate the tool status requires, urbane devices to frequently detect and respond to various optical, electrical signals. They convert physical parameters into digitally measured signals through electric pulses, by introducing a system of sensors installed at intimate absolute regions of machining. The installation after which it is a quite difficult task to generate dynamic parameters of motion, forces, fluctuation temperature and vibrations induced during the metal cutting process. The continuous monitoring is possible in the indirect non-contact method, where condition analysis is obtained from acquired signals which are difficult in analysing at the design of sensor locations. Rigorous research by Byrne et al. [3] in applications of focusing in machining operations of milling, drilling, grinding/ abrasion and turning processes shows that owing to an emphasis on tool failure/chipping/wear/collision, can be overcome with tool condition monitoring system of design industrially. Advancement in the design of multiple sensors for signal processing carried out in, time domain and frequency domain allowing to diagnose the condition of machining process from the information. Providing different types of tool failure, permitting us in the optimization of machining processes.

Known from the study of Ambhore et al. [4] which represents tool failure is unfavourably related to cutting tool wear, that being the root cause affecting the surface quality of the machined product. Thereby forming inaccuracy in dimensional requirements, which is avoided with optimization of optimum usage of the tool and cutting conditions. In the machining process, evidence showing tool life is affected dependent on cutting tool materials and cutting conditions are in proportionate, influenced by the workpiece materials like difficult-to-cut metals, oxide reinforcements. During machining, cutting conditions of cutting forces, temperature, torque etc., will be affecting tool life. These are also influenced by the type of reinforced particles, density, shape, and size of the particles forming composites. From the studies of Pramanik et al. [5] during machining of these composites, enormous cutting forces are generated due to the particle reinforcements of high hardness present. Giving out distributed strength to the composites causing higher wear rate in the cutting tool. Bains et al. [6] proposed from his studies showing wear in a straight-line affecting surface finish is due to the cutting parameters of speed, feed, and depth of cut. Hence monitoring the state of the cutting tool plays an important role in safeguarding the surface quality and optimum life of the tool, in machining complex structures which is a challenging task [7]. Real-time tool condition monitoring is evident to study, in extracting sensing features of cutting forces signals, vibration signals, and acousto opticemission signals during metal cutting operations. It is keenly evident that enormous research was carried out individually in the monitoring of cutting parameters, cutting condition and tool state during the machining process. Where a rigid design of a framework for the complete system in the monitoring of all the three states has not been studied collectively during the machining of composites. This led to a rise in efficient and accurate observations for future evolutions in the manufacturing process through data fusion analysis of signals, which extracted from monitoring the condition of any machining process (Fig. 1).

\section{Tool condition monitoring in machining}

Decades passed in the technically specialized research work carried out in monitoring the state of the machining process. Elbestawi et al. [8] suggested from his finding through the technique of data acquisition of signals extracted using sensors in locations based, which is capable of identifying machine glitches and diagnosis. The monitoring of machining process and condition of the tool can be known by both direct and indirect methods. Jantunen et al. [9] studies carried out on direct measuring methods of geometric dimensions, indirectly through monitoring of machining process (drilling operation). The condition of tool is monitored by measuring, forces and vibrations through approaches of fast four transforms and wavelet transforms varying cutting parameters. Precisely in the study of the machining process, diagnosis results in interpreting the direct effect of the tool influencing surface quality. Later from the investigations of Kurada et al. [10] involving monitoring the condition of the tool during any machining process considerably added importance to the system based on high-resolution vision sensors, providing clear image quality and accuracy. Hall et al. [11] described the use of multi-sensors in the monitoring of machining process had received significant attention evolving to an emerging technique. Thereby, applied in the areas of (DOD) department of defence in controlling autonomous vehicles and non-defence applications. One in which where a fusion of data from various type of multiple sensors assigned is combined, to improve accuracy in the total machining process.

\section{Multiple-sensor data fusion system in CNC machining}

Multi-Sensor Fusion of physiological measurements was introduced by Feldman et al. [12] in 1995 receiving a patent where the fusion estimated, enabled to create an 
Fig. 1 Schematic overview of fusion based tool condition monitoring

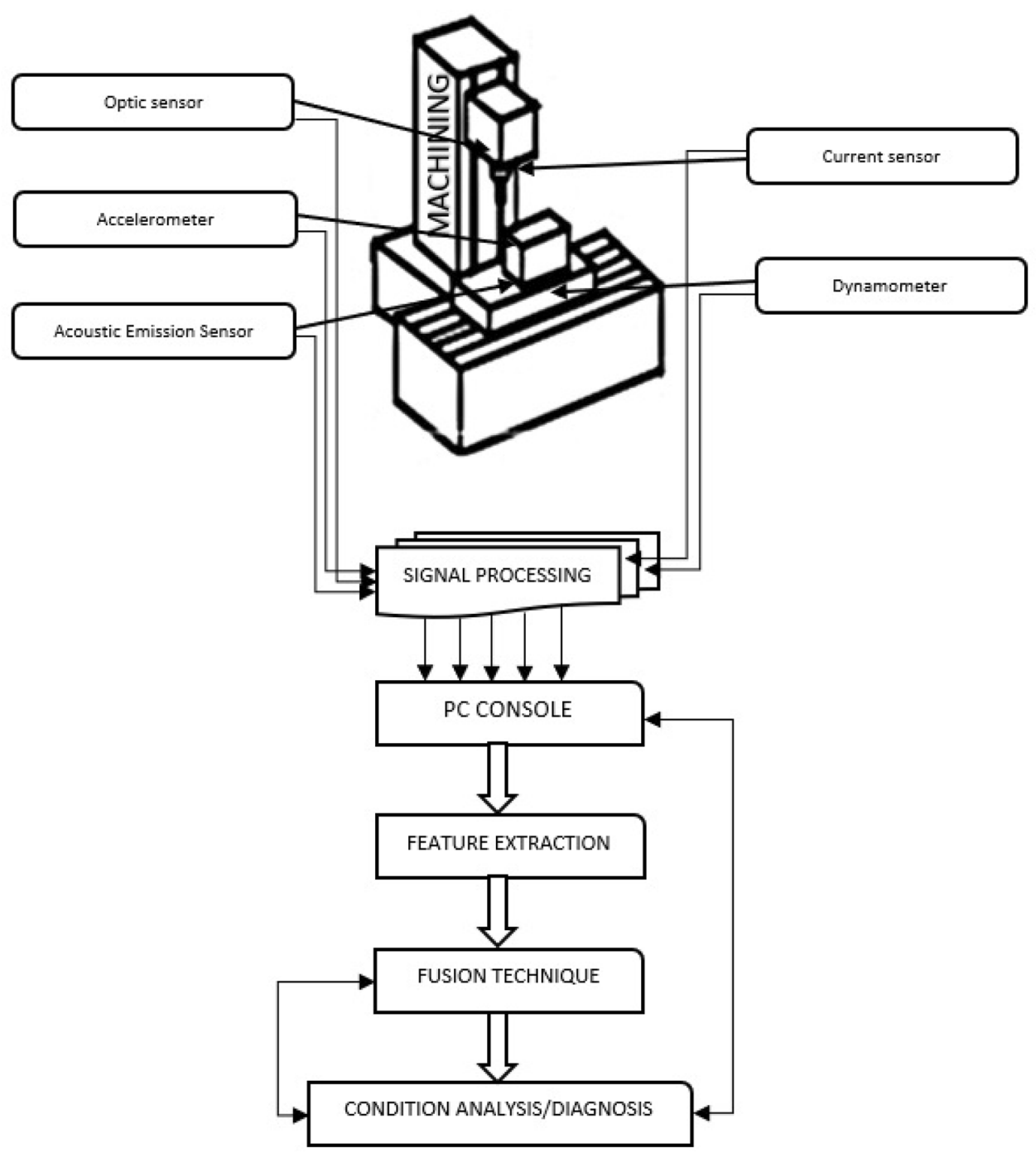

adaptive control measuring system producing a robust model growing confidence in error identification. Multisensor data acquisition system technique helps in integrating information from sensors which are technical extensions after estimation theory [13]. Data fusion system is integrated with CNC machining in recent years for economical and effective manufacturing processes. Nemati et al. [14] proposed a study in CNC milling of Al alloy of 6061-0 with two flute HSS tool, the acoustic emissions are calculated by installing $\mathrm{AE}$ sensors and microphones in and around the work enclosure. That revealed the best sensor signals from the locations installed for the given set of cutting parameters during machining along with the fatigue crack in the specimen, where the AE's are assessed from the cracks obtained. Data fusion has been implemented in one of the studies in diagnosing the vibrations generated and distributed in small amounts, from which patterns of vibration are examined by the waviness rollers and races in bearings caused by the vibrations induced. In this regard FAG, 6205 bearings are studied by Dolenc et al. [15] using CCLD 4508 accelerometer, and data retrieved using Data Acquisition Card (DAC) along with the values of amplitude. That is fused to analyze the condition of bearings concludes that vibrations patterns produced due to the surface finish of the rollers. Experimentation carried out by Grime et al. [16] incorporating nearly 150 sensors and more than 30 processors describing reorganized data fusion system revealing advantages in forming robustness and flexibility in monitoring the processes. Multi-sensor data fusion technique is based on different types of sensors like a tactile array, vision, force, position, cross-fire, weight sensors, proximity has been studied by Luo et al. [17] which are assigning to PUMA 560 robot illustrating a design of intelligent robot system. The system of sensor coordination reveals that the data from the sensors are fused in perceiving errors.

Several effective methods of data acquisition techniques using multiple sensors are addressed for online 
monitoring of tool in CNC milling centre by fusing the data as of extracted features from [18] KEYNCE AH 313 Accelerometer (Vibrations signals) and KISTLER 5019A Dynamometer (cutting forces) located to machine centre. Results revealing the fact that test performance increased significantly after fusing the data. The up-gradation in the monitoring of tool condition and machining centre by constructing an intelligent sensor monitoring system proved to be completely reliable in examining a study based on a neural network algorithm as shown in Fig. 2. Lou et al. [19] from investigations prove that the adaptive decision-making algorithm integrated with sensor information helped in making a suitable decision on the condition of the tool detecting tool breakage, tool failure, sensing techniques in detection of cutting forces and acoustic emissions (AE). Those are used in various studies which is an indirect method of evaluating vibrations, forces and sound in milling with intermittent frequency. Tönshoff et al. [20] studies show that features evaluated from the measurement of signals help in framing a model for cutting parameters.

\section{Sensors based on data acquisition}

The literature survey reveals data acquired during machining involved in monitoring different process parameters such as cutting forces, acoustic signals, temperature, current, vibrations etc., are sensible in predicting the tool life in identifying the required type of sensors to be allocated. Depending upon the condition and state of the process, the cryogenic machining using machining operations like milling and drilling with different combined alloyed materials is essentially maintained through control sensors [21]. Another way to monitor the machining process involving retrieval of emission signals during machining of composite materials using wavelet transforms which is a tool. This helps in detecting the condition of the drill
Fig. 2 Strategy of multi-sensor data fusion system in machining diagnosis

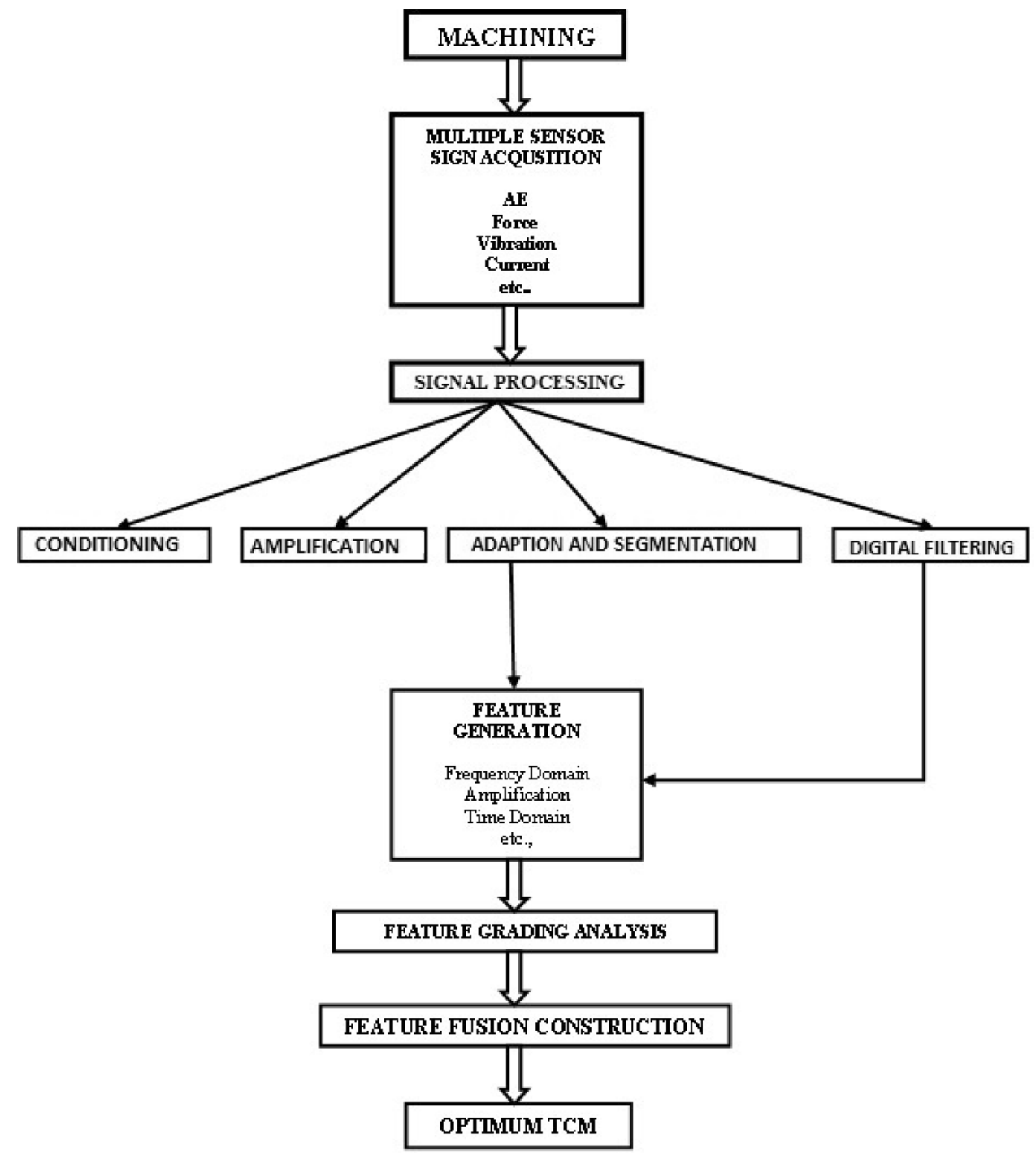


effectively [22]. Research studies involving machining process occurred with a carbon-coated cutting tool having a cost-effective in the outcome of the products. Coated tool during the machining process results in delamination causing tool failure. So as to study the failure of the tool it is important to know parameters affecting it. Therefore, a study carried out on investigation condition of machining metal matrix using dynamometer sensor results in the evaluation of tool wear [23]. Diagnosing the fault in tool plays an important role in defining the quality of the product. Assigning multiple sensors in acquiring information about several time-frequency domains (wavelet transforms) which are also selected as an alternative during machining [24]. Understanding the fundamentals of complex means of tool failure in monitoring machine condition and embedding new methods of finding aimed at high-quality research [25]. Tool condition monitoring one vital method of manufacturing augments based on sensor wireless communication, cost-effective with multiple sensor tool condition monitoring developed. Data collected from various sensors such as cutting forces, power, vibrations data and acoustic data alongside with machining parameters enables support for monitoring condition of the tool and estimating tool life [26]. Successful implementation of tool condition monitoring in automated plants states tool fracture, tool wear, chatter, built-up-edges, chip type, runout etc. followed by decision-making algorithms [27] also in the machining of composites. Unlike a unique multi-sensor TCM system implemented for diagnosing turning operations by using vision and vibrations sensors. Signals of obtained vibrations are monitored online with an accelerometer mounted in the tool holder which is an upgrading approach through a vision sensor system. This approach combines direct (vision) and indirect (vibrations) monitoring technique on-line, increasing the consistency of the TCM system [28]. So far regarding sensor system, the technical contests required for the functioning of tool condition monitoring system has been understood. Focusing on the development of a multiple sensor tool condition monitoring systems, it is purely significant to distinguish the sensors selectively.

\section{Sensor selection in fusion-based TCM}

Having intimidated equipment's which give complexity and high loads impacts onto the machining process so as to define the monitoring, it is easily installed and retrieved data in the form of signals using sensors. The sensors pertain the need for portability in installation and examination of any process outcomes [29]. Therefore, it is taken as an important aspect of using sensors for continuously monitoring the machining process by detecting momentous changes occurred during cutting. As from the review of research literature, the problems identified affecting the machining process involved tool [30] failure, chatter, wear etc. These cannot be identified or observed through visually which required sensors. So as to identify the possible reasons affecting the machining processes, sensors used are of the direct and indirect mode of examination [10]. It is imperative to follow the indirect method of sensing and analysing for their easy to use the property. Indirect methods of sensory observations include measuring of forces and emission signals [31]. The installation of sensor system satisfies the requirements of obtaining information periodically, it doesn't interfere the coordination of the machine tool and machining process, easily installed in the suitable near to locations obtaining high resolution monitoring output [32].

\section{Types of sensors and implementation}

Most predominantly various sensor types are selected depending on the output parameters in the machine monitoring process during machining. Basically, sensors of obtaining acoustic emission signals [33], force sensors [34], acceleration sensors [35], current sensors [36], optical sensors [37], etc., are required to full fill the assessment of the condition of the machining process. Each sensor having designated effect of information accessing capability, literature from the past shows that the use of these sensors effectively shows reliable results in identifying the flaws in the machining process. Results favourable shows that tool breakage monitored with measuring an increase in force in machining [38]. Whereas satisfactory results are obtained using optical sensors in monitoring the quality of the machining output through quality analysis [39] this is a direct method of sensing information. Optic sensory information process is only cost-effective process of obtaining information resulting in paying attention in installation and in order to avoid affecting the machining process resulting in morphology image processing technique [40], detecting tool failure. Using high-resolution optical sensors, it is evident from the previous finding that the wear of the tool is responsible for tool failure through processing images. This method of retrieving data is suitable for turning, grinding, and milling process. It is also important to identify suitable sensor location [41] so as to suitably fit the requirement of obtaining data periodically to the best resolution without affecting the machining process or affected by by-products of the metal removal process. Therefore, in recognizing entire condition [42] of the tool, basic system of multiple sensors essential are of effectively monitoring cutting forces, based strain energy, vibrations, temperature and visuality. 


\subsection{Dynamometer-cutting forces influence in machining MMC tool wear vs cutting forces}

Gradually increased tool wear increases the cutting forces which is significantly judicious to tool failure evident from the previous research findings. The need for measuring the cutting forces caused the intervention of dynamometer as sensor measuring three directional forces acting along the $x$-axis, $y$-axis, and $z$-axis. The data is acquired in the form of Fast Fourier Transforms with time-frequency domain analysis from the sensor's locations of the cutting region along with position tracking [43]. One of the experimental forces is predicted from the servo drives authenticated on 5-axis machining centre of Heidenhein CNC machine. Forces at the tooltip in $\mathrm{x}, \mathrm{y}$ and $\mathrm{z}$ directions are observed in CNC machining revealed accurately using sensors at desired locations of the tool for achieving intelligent self-learning adaptive tool condition monitoring [44]. Therefore, in order to attain fewer cutting forces which directly affecting tool life vice versa surface quality evidentially depends on cutting parameters of feed, speed, and depth of cut. Experiments conducted in CNC milling of Aluminium alloy of 2024-T351 programmed to analyse cutting forces taking optimised full factorial statistical parameters employing dynamometer along with the optical profilometer to measure surface roughness. This concludes that optimizing the machining process to obtain lower cutting forces shows a significant increase in surface quality [45]. Some revisions show the surface quality is affected based on structure and characteristics of the material machined which are responsible for a substantial increase of cutting forces during experimentation performed on atomized aluminium alloy of AA-7039 MMC, milled with VMC550 tri-axis CNC machine using standard carbide cutting tool and tie cutting forces are extracted [46].

\subsection{Acoustic emission (AE) sensor-tool failure mechanism in machining MMC's}

Acoustic emission is a non-contact method of detecting strain energy at a location of discontinuity in the form of elastic waves. One can easily identify the mechanism of local failure at regions using $A E$ such as material behaviour and mechanism of fracture through continues monitoring the entire volume of material and alloys. Investigations from Henneke et al. [47] studies show that the failure mechanism in boron-epoxy aluminium laminates by monitoring using acoustic emission counting based on the function of time. AE transmitted shows failure mechanism in tensile load for combinations of effects caused in the presence of metal. The failure mechanisms (metal cracking, interfacial debonding and fracture) are studied by the sounds recorded at regions during structural deformations of crack propagations in metals through $A E$ sensors as presented in Fig. 3. An attempt made in understanding failure in composites individually by Mehan et al. [48], AE signals used in analysing the local failure by a low mass accelerometer attached to the surface of boron-epoxy composites, where signals stored in magnetic tapes for summing up of totally emitted acoustic emission signals. Importance in finding the failure mechanism in the tool is mainly due to which is a reason for directly affecting productivity has been predominant till date. However, the concept of tool condition monitoring (TCM) sensor-based machining is tremendous at its importance for casting tool wear. Previous observations by Patra et al. [49] found in machining process such as drilling which is carried out on mild steel using HSS where AE signals facilitated in identifying flank wear. A study from Velayudham et al. [22] shows, drill condition in the machining of polymer glass/phenolic composites with HSS are monitored using Kistler piezoelectric $A E$ sensor, which is located on workpiece acquired $A E$ signals processed as wavelet transforms and flak wear of the tool using a universal microscope. The Study observations reveal the relativity between wavelet form affecting flank wear. It is important to study the status of the tool as it

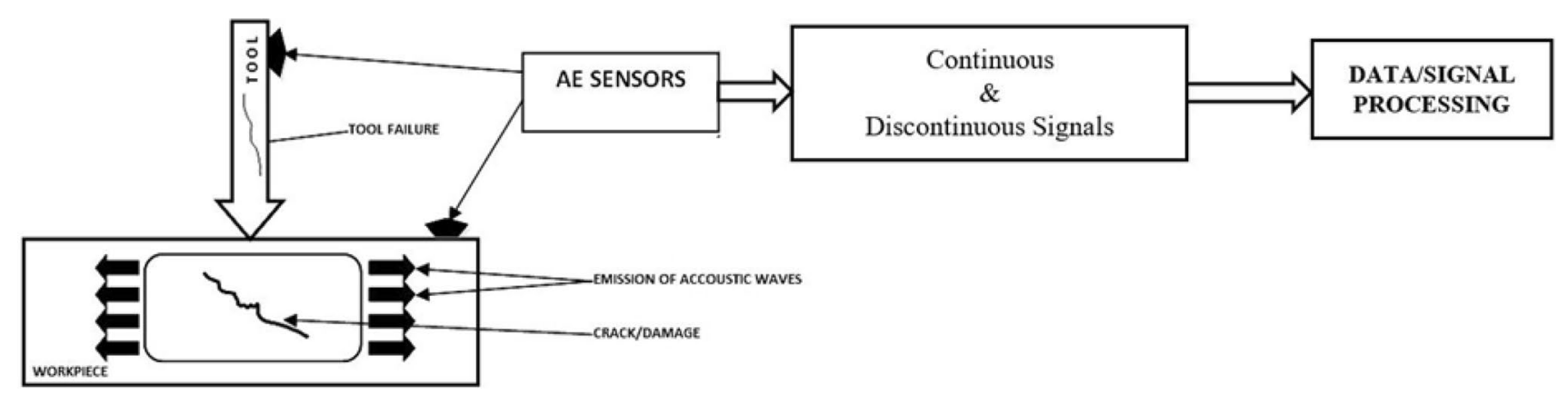

Fig. 3 Acoustic emissions during tool failure mechanism [47] 
plays a prominent role in any metal removal process or else results in non-uniform downtime from the worn-out tool. Many methods have been studied in finding out the condition of the tool from which online observation came into account while performing a metal removing process i.e., TCM. Known precisely that cutting forces in motion and in the static state along with vibrations are more predominant parameters causing the failure of the tool.

Dimla et al. [50] studies show that established TCM system didn't been used fruitfully due to the scare of information from the sensors while machining. Development of a determining technology for continues computing of the parameters that are responsible for tool wear is crucial. Therefore, it is essential to develop a standard system of technology of analysing and diagnosing the ailment of the tool such as tool breakage, chipping, level of tool wear etc., continuously. Thus, a system involved in sensors of AE had been an advantage in any machining process in pulling out signal information from the varied condition of the tool in the process of metal removing. AE signals acquire data in the form of continues (obtained from shear in primary zone wear of tool flank) and discontinue (signals obtained during tool breakage or fracture) signals deriving various characteristics. Methods of analysing these continues and discontinues signals involve Fast Fourier Transforms, Time Domain analysis, Wavelet Transforms, WignerVille method, and Gabor Transforms [51]. Finding from Li et al. [52] in the drilling of glass-woven fibre composite along with epoxy resin LY-556 and hardener HT-972 made into a compressed workpiece with a volumetric fraction of 0.4 in which AE signals were processed obtained from parameters of RMS and peak power. These results reveal that cutting parameters influence forces proportionally on tool wear. The forces are increased with the rate of feed in the drilling process influencing tool wear where optimized cutting parameters observe minimum tool wear. The observations [53] reveal an accurate relationship between acoustic emission signal and flank wear in machining depends on input/output parameters revived. The measurement of torque and $A E$ by evaluation chip formation in drilling of AISI 1040 steel workpiece was presented. The torque was analysed using torque cell which was synced with $\mathrm{AE}$ with a threshold of $27 \mathrm{~dB}$. Results show that high torque damages the cutting edges of the tool resulting in wear identified using AE sensors [54]. Influence of Machining parameters on wear when drilling process carried out with a diamond-coated tool on aluminium MMC's, low tool wear with increased flank caused with delamination caused by coating proportional rate of increase in cutting forces is observed by AE sensors. The coatings on tools are delaminated during the machining process is observed [55]. During face milling, the chip formation affecting flank wear with parameter counts in-process monitoring of the position of the chip along with tool condition is monitored using AE Piezo-electric sensors. A pre-amplifier amplifies the signal at $40 \mathrm{~dB}$ which are sent to the data acquisition system where chip status is monitored using a tool maker's microscope at a limit of $0.3 \mathrm{~mm}$ machining. It is found that, increased tool wear with material dislodgment from the flank surface resulting in discontinues signals resulting in tool failure [23].

\subsection{Accelerometer-vibrations signals in Tool failure mechanism in machining MMC's}

During the machining process, the tool centre tends to displace from its original position driven to elliptical orbits losing contact with chip involving the distribution of induced forces, resulting in tool wear. The vibrations induced during machining obtaining amplitudes with high-frequency form displacement of tool leading to affect surface finish. A vibration-assisted system is implemented during machining of steel with polycrystalline diamond tool producing more wear which is rectified by the parametric conditions. VAM (Vibration Assisted Machining) having advantages over the machining process in reducing cutting tool forces, improved tool life with accuracy in surface finish and from burr formation [56]. The uncontrolled vibrations can affect any machining process lead to chatter affecting tool life and quality of the finish. The effort in considering the improved machining process is in finding out the vibrations and reducing the induced vibrations. A study involving milling of steel and aluminium call for active-controlled system dynamics so as to improve surface finish. The self-excited and forced vibrations are due to cutting loads acting on the workpiece. These vibrations are minimised by the error rectification from the sensor which is measured using the accelerometer for controlling the vibrations [57]. An Experimental study shows that a turning process done with diamond tool inserts on $\mathrm{MMC} /$ aluminium reinforced alongside silicon particles in $\mathrm{CNC}$, installed with a vibration sensor, roughness is considered with microtopography by which the study with three measurements for every sample affected with an effect of ultrasonic vibrations. The comparative study of machining based on ultrasonic vibrations, without resulting speed and depth of cut affecting surface quality [58].

The previous study involves performance characteristics factors such as vibrations, surface roughness etc. The machine parameters are optimized using orthogonal array method [59]. The tool wear/vibration relationship was investigated during milling with CBN inserts of AISI D3 steel tool having hardness 30 and the vibrations induced are tracked using accelerations sensor that is Accelerometer located to the machine tool. The induced vibrations obtained from a sensor located at the tool position where 
signals are captured relating the tool wear with vibrations, tool wear with displacement and tool wear with frequency as shown in Fig. 4 at which spindle rotates constantly. Results reveal that increased vibrations caused tool wear which is measured with tool-makers microscope along with an increase in displacement and velocity [60]. PDC tools used for cutting steel are monitored for tool wear analysis by installing a transducer (Accelerometer). The study of reducing the cutting forces using ultrasonic sensor is once again revised informing reduces in wear along with temperature generations [61]. Effect of ultrasonic vibration of the tool on EDM (Electrical Discharge Machining) in the machining of tungsten carbide showed observations of the effect of high MRR (Metal Removal Rate) worked with Low discharge currents. The vibrations induced are high affecting the tool wear and surface roughness [62]. An experimental study of vibrations amplitude in rotatory ultrasonic machining (RUM) in machining ductile, brittle and composite materials along with process variables affect the output. A measuring technique in measuring vibration amplitude with a distance from the peak-to-valley trajectory is studied, using high magnification pictures obtained from microscopic observations. Five diamond tools were used in machining, show different vibrations amplitude without rotary ultrasonic machining [63].

\subsection{Temperature analysis-machining of MMC's}

In advanced machining of composites, high temperature prevails along the tool causing tool wear due to the abrasiveness between the phases of workpiece materials. The reductions of the temperature being one of the major roles in reducing tool wear, experiments in machining composites with diamond coated tools are monitored for its tool wear rate due to elastic modulus, thermal coefficients. The possibility of reducing the temperature is studied in increasing the tool life using passive heat pipe and thermocouples installed. Results show higher heat flux is generated in the tool with increased cutting speed and feed finally leads to quick tool wear [64]. Materials such as $\mathrm{SiC}$ having higher hardness and thermal expansion which are found in studies, in the machining of MMC of Al6061 based varying increased weight of $\mathrm{Cu}$. This increases the impact strength and hardness at a temperature of 700 degrees centigrade reveals that the pouring rate doesn't affect the metal removal rate [65]. Several research investigations propose effect of an increase in temperature due to parameters of speed, feed, and tool materials used resulting in tool wear. So, the importance of measuring these temperatures is necessary for condition monitoring of the tool. One of the studies showing aluminium series reinforced with three composite particles were drilled in CNC vertical machine at a speed of 3500 Rpm using HSS, uncoated and TiAIN coated carbide drill bit. The emissivity is measured using Pyrometer as demonstrated in Fig. 5 which is a non-contact measuring method of temperatures in tool-workpiece locations. Findings from Taskesen et al. [66] show that emissivity of the tools is less observed when the temperatures are less than 500-degree centigrade and suddenly increased. Optimised parameters reveal that increased feed rate decreases cutting temperature

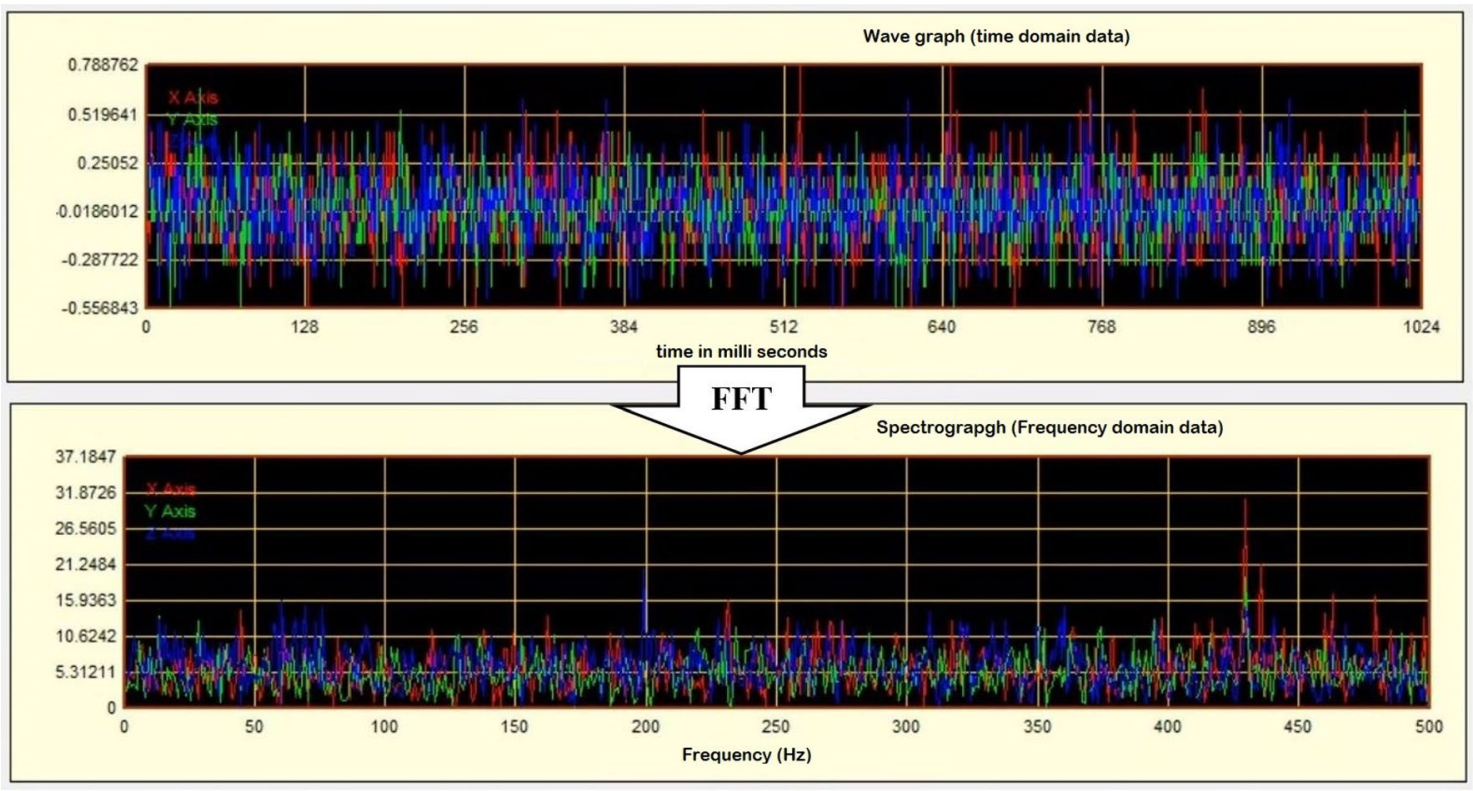

Fig. 4 Vibrations measured by time-domain analysis and frequency displacement [59] 


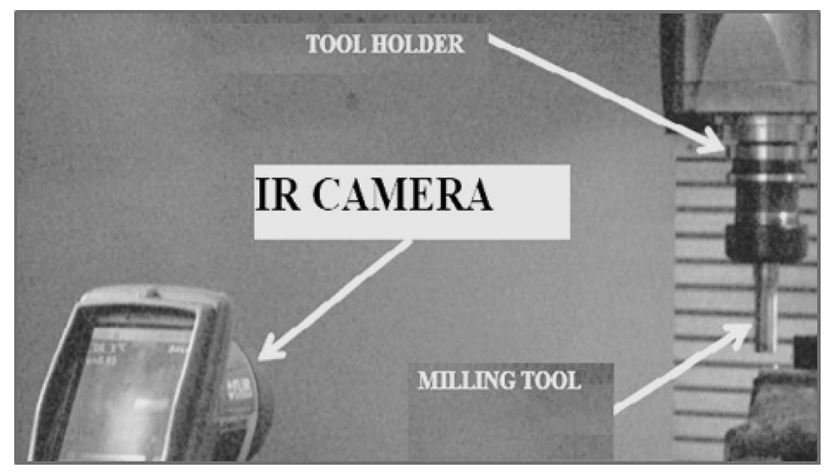

Fig. 5 Pyrometer in temperature analysis [66]

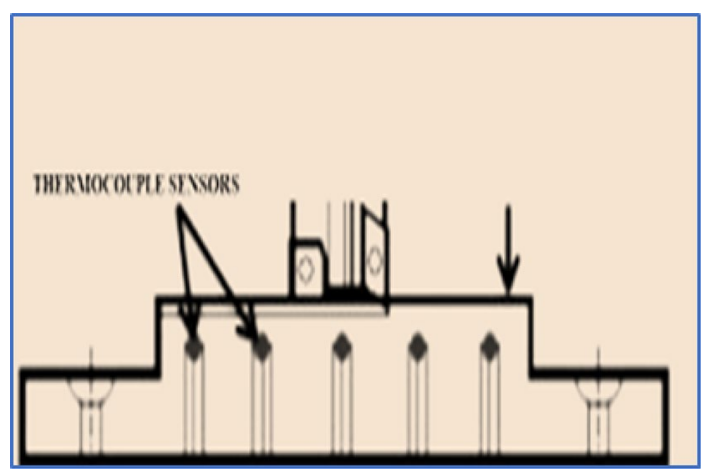

Fig. 6 Thermocouples installed [64]

because of the formed cutting chip in a free flow rate [67]. Chips formation intend due to cutting forces responsible for the formation of plasticity in primary and secondary deformation areas resulting in the increased temperature leading to tool wear. Experiment on new materials intends to study the temperatures prevailing during turning process when Al6061 based metal matrix composites machined with carbide tool materials.it is observed that temperature is maximum at tool contact with chip interface having speeds of $50 \mathrm{~m} / \mathrm{min}$ which is 315 -degree centigrade [68]. MMC materials of AISiC are machined with EDM resulting in the distribution of temperature which is studied based on thermocouple presented in Fig. 6. Whereas current-voltage referring to combinations of Taguchi L9 orthogonal array method of analysis using Minitab, results in higher temperature observed at higher current and low for less voltage [69]. The thermal signatures developed in turning operations showing the dependant of microstructural particle nature of the workpiece of AISiC judged with increased temperature along with stresses affecting the tool life to perceive tool wear. Depending upon the cutting parameters, tool materials, and geometry, the tool wear is analysed incorporating temperature analysis [70]. Similarly, the temperature distribution in the machining of multi-layer metal composite generating critical temperatures predicted using TEMSS program is calculated. Grinding leads to defects in finish material involving elevated temperatures dependent on conditions of tool-workpiece when contact and along with material structure. The analysis of temperatures depending on the structure of machined materials helps in preparing guidelines of temperatures for various metal composite structures during experimentation and investigations [71].

For example, the analysis of temperatures depending on the structure of machined materials helps in preparing guidelines of temperatures for various metal composite structures during experimentation and investigations.

\section{Critical discussion: future holistic approach}

The literature review represents various methodologies in studying the fabrication and machining of various composites thereby studying of diagnosing the faults and constraints.

Very few researchers undergo machining of composites, among which some of them are Glass fibre reinforced in PA66 GF-30 Polyamide. The study involves cutting forces dependent on cutting parameters [72]. Sporadic Explorations involving machining of the tailored-made composite such as 316-1 stainless steel flakes reinforced into aluminium matrix, where speed, feed with varied DOF is constant [6]. Whereas some methods of involving the experimental design with the L9 orthogonal array method for which material waste and machining time is reduced. As from the study, the optimization technique is used in improving the quality of the machining [73]. Thereby pace to the Futuristic investigations includes various composites patterns. The au fait complete review represents various methodologies intricating preparation and machining of composites. Study of literature gave a contrast for further, holistic futuristic machining best suitable polycrystalline tools. The focus of the literature mainly tends gave away to the futuristic ideology as in developing a seamless practice in the machining of tailored made nanocomposites. This can be achieved by exploring machining strategies through analysing cutting routes according to external machining parameters, which presents an au fait advancement in machining and fabrication of MMC's. From practical scrutinise of dialects and finding, the uncountable results elaborates various issues occurred in the fabrication and machining of MMCs. Beyond concluding that polycrystalline tools and diamond-coated tools are best suitable for various conventional machining operations represents the enormous works performed in hybrid MMC's. Machining of composites with respect to speeds, feeds 
Table 1 Summary of sensors and methods in multiple sensor data acquisition technique

\begin{tabular}{llll}
\hline S.no & Sensors type & Measuring method & Citation \\
\hline 1 & Acoustic emission (AE) & Non-contact & $34,47-57$ \\
2 & Force sensors & Non-contact & $19,23,35,44-46$ \\
3 & Acceleration sensors & Contact and non-contact & $36,58-65$ \\
4 & Current sensors & Direct and indirect method & $37,64,71$ \\
5 & Optical sensors & Non-contact & $38,40,42$ \\
6 & IR sensors & Non-contact & $66-73$ \\
8 & Vision sensors & Non-contact & 10 \\
\hline
\end{tabular}

and depth of cut. The machining of Hybrid nano MMC's reinforced with difficult-to-cut nanoparticles can lead to reduced tool life which requires more energy rapidly causing flank wear [74]. These were a major drawback, the challenging chore in identifying wear features which is a concentrated task for investigating failure and fault during machining. This brought a scope from previous observations, that the study of fault and failure during machining originated using sensor technique dependent on sensor type. By dedicated sensors implementation at locations, so as to derive the signals from the sensors indicate the occurrence of a failure in machining [75]. Which vice versa informing flank wear dependant on error/fault in machining. The framework brings out evolution in detecting the failure in machining carried out with diagnosis majority facing delinquent. By designing and diagnosing through framework system which an in-situ technique recognizing the fault, which results in bringing an addition to the space-age resolution. The commitment of the literature review required so as to implement a framework system of multiple sensors, which signals detected are fused in the machining of composites helps in ample machining diagnosis. This designates in exploring machining strategies by analysing cutting routes according to external machining parameters that are essential to investigate how extreme outputs in machining parameters could influence tool life. The overall summary of sensors and method of measurements are shown in the Table 1.

\section{Conclusion}

The review of various sensors for building the framework of a system is studied for fault detection and failure identification in machining process. Assigning the techniques of sensor fusion based TCM it is found that from the sensor signals features, it is possible to accurately supervise the elemental factors causing wear in tool and the sundry parameters impacting wear relatively. Considering parameters of cutting speeds along with temperature analysis is a rare study having the best option in finding out the tool wear in less monitoring time. In finding out the various attributes causing tool wear, an instant feedback system is required forming a system of multiple sensor fusion based tool condition monitoring. Machining of advanced developed MMC's lead to an era of new metal combinations for economic growth in the materialistic environmental achievements. The challenging task is to recognize the wear featuring geometry of the cutting tool and reasonable unknown factors, accountable in affecting machining of Hybrid Metal Matrix Composites by integrating multiple sensor fusion technique. From the fused sensory data procured $[76,77]$ through response signals are useful to find the cause and avoid excess wastage of metal besides the cutting forces and effect of structure which is rarely studied during machining. In order to overcome this obstacle, the review is focused in presenting the methodology, includes the study of (1) The tool/workpiece condition monitoring in machining, (2) Multiple sensor fusion based monitoring in machining hybrid metal matrix composites, (3) Different sensors required for rigorous condition monitoring during machining, and (4) The fusion based diagnosis of machining process in Hybrid nano MMC's [78, 79]. This process of fusion based system alignment shows the possibility of inspecting various factors affecting the machining process. This multiple sensor fusion system which will be keenly for analysing and diagnosing of any machining process. Such as analysing the temperature, vibrations, etc. that are dependent on machined materials are responsible for causing tool failure. These outcomes help us in preparing guidelines for various matrix materials machined during experimentation and investigations.

Acknowledgements This research is sponsored by the Science and Engineering Research Board (SERB) with sanction order No. SB/FTB/ ETA-0262/2013. The authors wish to gratefully acknowledge the financial support provided for this study by the Department of Science and Technology, Govt.of India, New Delhi.

\section{Compliance with ethical standards}

Conflict of Interest The authors declare that they have no conflict of interest. 


\section{References}

1. Duro JA, Padget JA, Bowen CR, Kim HA, Nassehi A (2016) Multisensor data fusion framework for $\mathrm{CNC}$ machining monitoring. Mech syst signal process 66:505-520

2. Yesilyurt I, Ozturk H (2007) Tool condition monitoring in milling using vibration analysis. Int J Prod Res 45(4):1013-1028

3. Byrne G, Dornfeld D, Inasaki I, Ketteler G, König W, Teti R (1995) Tool condition monitoring (TCM) - the status of research and industrial application. CIRP Ann Manuf Technol 44(2):541-567

4. Ambhore N, Kamble D, Chinchanikar S, Wayal V (2015) Tool condition monitoring system: a review. Mater Today Proc 2(4-5):3419-3428

5. Pramanik A, Zhang LC, Arsecularatne JA (2006) Prediction of cutting forces in machining of metal matrix composites. Int J Mach Tools Manuf 46(14):1795-1803

6. Bains PS, Sidhu SS, Payal HS (2016) Fabrication and machining of metal matrix composites: a review. Mater Manuf Process 31(5):553-573

7. Liu C, Li Y, Hua J, Lu N, Mou W (2018) Real-time cutting tool state recognition approach based on machining features in NC machining process of complex structural parts. Int J Adv Manuf Technol 97(1-4):229-241

8. Elbestawi MA, Dumitrescu M (2006) Tool condition monitoring in machining-neural networks. In: Information technology for balanced manufacturing systems. Springer, Boston, pp 5-16

9. Jantunen E (2002) A summary of methods applied to tool condition monitoring in drilling. Int J Mach Tools Manuf 42(9):997-1010

10. Kurada S, Bradley C (1997) A review of machine vision sensors for tool condition monitoring. Comput Ind 34(1):55-72

11. Hall DL, Llinas J (1997) An introduction to multisensor data fusion. Proc IEEE 85(1):6-23

12. Feldman JM, Ebrahim MH, SpaceLabs Medical Inc, (1997). System and method of multi-sensor fusion of physiological measurements. U.S. Patent 5,626,140.

13. Crowley JL, Demazeau Y (1993) Principlses and techniques for sensor data fusion. Signal process 32(1-2):5-27

14. Nemati N, Metrovich B, Nanni A (2015) Acoustic emission assessment of through-thickness fatigue crack growth in steel members. Adv Struct Eng 18(2):269-282

15. Dolenc $B$, Boškoski $P$, Juričić $Đ$ (2016) Distributed bearing fault diagnosis based on vibration analysis. Mech Syst Signal Process 66:521-532

16. Grime S, Durrant-Whyte HF (1994) Data fusion in decentralized sensor networks. Control eng pract 2(5):849-863

17. Luo RC, Lin MH, Scherp RS (1988) Dynamic multi-sensor data fusion system for intelligent robots. IEEE J Robot Autom 4(4):386-396

18. Chen SL, Jen YW (2000) Data fusion neural network for tool condition monitoring in CNC milling machining. Int J Mach Tools Manuf 40(3):381-400

19. Lou KN, Lin CJ (1997) An intelligent sensor fusion system for tool monitoring on a machining centre. Int J Adv Manuf Technol 13(8):556-565

20. Tönshoff HK, Wulfsberg JP, Kals HJJ, König W, Van Luttervelt CA (1988) Developments and trends in monitoring and control of machining processes. CIRP Ann Manuf Technol 37(2):611-622

21. Shokrani A, Dhokia V, Muñoz-Escalona P, Newman ST (2013) State-of-the-art cryogenic machining and processing. Int J Comput Integr Manuf 26(7):616-648

22. Velayudham A, Krishnamurthy R, Soundarapandian T (2005) Acoustic emission based drill condition monitoring during drilling of glass/phenolic polymeric composite using wavelet packet transform. Mater Sci Eng A 412(1-2):141-145
23. Qin F, Hu J, Chou YK, Thompson RG (2009) Delamination wear of nano-diamond coated cutting tools in composite machining. Wear 267(5-8):991-995

24. Zhou Y, Xue W (2018) A multisensor fusion method for tool condition monitoring in milling. Sensors 18(11):3866

25. Javaheri V, Porter D, Kuokkala VT (2018) Slurry erosion of steelReview of tests, mechanisms and materials. Wear 408:248-273

26. Zhang XY, Lu X, Wang S, Wang W, Li WD (2018) A multi-sensor based online tool condition monitoring system for milling process. Procedia CIRP 72:1136-1141

27. Cho DW, Lee SJ, Chu CN (1999) The state of machining process monitoring research in Korea. Int J Mach Tools Manuf 39(11):1697-1715

28. Bahr B, Motavalli S, Arfi T (1997) Sensor fusion for monitoring machine tool conditions. Int J Comput Integr Manuf 10(5):314-323

29. Shieh J, Huber JE, Fleck NA, Ashby MF (2001) The selection of sensors. Prog Mater Sci 46(3-4):461-504

30. Cook DJ, Holder LB (2011) Sensor selection to support practical use of health-monitoring smart environments. Wiley Interdiscip Rev Data Min Knowl Discov 1(4):339-351

31. Liang SY, Hecker RL, Landers RG (2002) Machining process monitoring and control: the state-of-the-art. In: ASME 2002 international mechanical engineering congress and exposition. American Society of Mechanical Engineers, pp 599-610

32. Lanzetta M (2001) A new flexible high-resolution vision sensor for tool condition monitoring. J Mater Process Technol 119(1-3):73-82

33. Li F, Yu Z, Yang Z, Shen X (2019) Real-time distortion monitoring during fused deposition modeling via acoustic emission. Struct Health Monit. https://doi.org/10.1177/14759 21719849700

34. Kene AP, Choudhury SK (2019) Analytical modeling of tool health monitoring system using multiple sensor data fusion approach in hard machining. Measurement 145:118-129

35. OSHETSKI M, Pradhan A, Micatu Inc, (2019) Enhanced optical condition monitoring system for power transformer and method for operating power transformer. U.S. Patent Application 10/215,621.

36. Hanachi H, Yu W, Kim IY, Liu J, Mechefske CK (2019) Hybrid datadriven physics-based model fusion framework for tool wear prediction. Int J Adv Manuf Technol 101(9-12):2861-2872

37. Mehta S, Singh RA, Mohata Y, Kiran MB (2019) Measurement and analysis of tool wear using vision system. In: 2019 IEEE 6th international conference on industrial engineering and applications (ICIEA). IEEE, pp 45-49

38. Xing K, Achiche S, Mayer JRR (2019) Five-axis machine tools accuracy condition monitoring based on volumetric errors and vector similarity measures. Int J Mach Tools Manuf 138:80-93

39. Wu H, Li R, Kwok NM, Peng Y, Wu T, Peng Z (2019) Restoration of low-informative image for robust debris shape measurement in on-line wear debris monitoring. Mech Syst Signal Process 114:539-555

40. Liu MK, Tseng YH, Tran MQ (2019) Tool wear monitoring and prediction based on sound signal. Int J Adv Manuf Technol 103(9-12):3361-3373

41. Postel M, Aslan D, Wegener K, Altintas Y (2019) Monitoring of vibrations and cutting forces with spindle mounted vibration sensors. CIRP Annals 68:413-416

42. Prasad BS, Prasad DS, Sandeep A, Veeraiah G (2013) Condition monitoring of CNC machining using adaptive control. Int J Autom Comput 10(3):202-209

43. Jáuregui JC, Reséndiz JR, Thenozhi S, Szalay T, Jacsó Á, Takács M (2018) Frequency and time-frequency analysis of cutting force and vibration signals for tool condition monitoring. IEEE Access 6:6400-6410 
44. Aslan D, Altintas $Y$ (2018) Prediction of surements. IEEE/ASME Trans Mechatron 23(2):833-844

45. Bolar G, Das A, Joshi SN (2018) Measurement and analysis of cutting force and product surface quality during end-milling of thin-wall components. Measurement 121:190-204

46. Fountas NA, Benhadj-Djilali R, Stergiou Cl, Vaxevanidis NM (2019) An integrated framework for optimizing sculptured surface CNC tool paths based on direct software object evaluation and viral intelligence. J Intell Manuf 30(4):1581-1599

47. Henneke EG, Herakovich CT, Jones GL, Renieri MP (1975) Acoustic emission from composite-reinforced metals. Exp Mech 15(1):10-16

48. Mehan RL, Mullin JV (1971) Analysis of composite failure mechanisms using acoustic emissions. J Compos Mater 5(2):266-269

49. Patra K (2011) Acoustic emission based tool condition monitoring system in drilling. In: Proceedings of the world congress on engineering, vol 3, pp 6-8

50. Snr DED (2000) Sensor signals for tool-wear monitoring in metal cutting operations-a review of methods. Int J Mach Tools Manuf 40(8):1073-1098

51. Jeng YN, Cheng YC (2006) A time-series data analyzing system using a new time-frequency transform. In: First InternationalConference on Innovative Computing, Information and ControlVolume I (ICICIC'06), September. IEEE, pp 525-528

52. Li X (2002) A brief review: acoustic emission method for tool wear monitoring during turning. Int J Mach Tools Manuf 42(2):157-165

53. Arul S, Vijayaraghavan L, Malhotra SK (2007) Online monitoring of acoustic emission for quality control in drilling of polymeric composites. J Mater Process Technol 185(1-3):184-190

54. Hutton DV, Hu F (1999) Acoustic emission monitoring of tool wear in end-milling using time-domain averaging. J Manuf Sci Eng 121(1):8-12

55. Gómez MP, Hey AM, D'Attelis CE, Ruzzante JE (2012) Assessment of cutting tool condition by acoustic emission. Procedia Mater Sci 1:321-328

56. Kakade S, Vijayaraghavan L, Krishnamurthy R (1994) Inprocess tool wear and chip-form monitoring in face milling operation using acoustic emission. J Mater Process Technol 44(3-4):207-214

57. Brehl DE, Dow TA (2008) Review of vibration-assisted machining. Precis eng 32(3):153-172

58. Rashid A, Nicolescu CM (2006) Active vibration control in palletised workholding system for milling. Int J Mach Tools Manuf 46(12-13):1626-1636

59. Prasad BS, Sarcar MMM, Ben BS (2010) Development of a system for monitoring tool condition using acousto-optic emission signal in face turning - an experimental approach. Int J Adv Manuf Technol 51(1-4):57-67

60. Rajesh S, Devaraj D, Pandian RS, Rajakarunakaran S (2013) Multiresponse optimization of machining parameters on red mudbased aluminum metal matrix composites in turning process. Int J Adv Manuf Technol 67(1-4):811-821

61. Orhan S, Er AO, Camuşcu N, Aslan E (2007) Tool wear evaluation by vibration analysis during end milling of AISI D3 cold work tool steel with 35 HRC hardness. NDT E Int 40(2):121-126

62. Zhou M, Eow YT, Ngoi BKA, Lim EN (2003) Vibration-assisted precision machining of steel with PCD tools. Mater Manuf Process 18(5):825-834

63. Abdullah A, Shabgard MR (2008) Effect of ultrasonic vibration of tool on electrical discharge machining of cemented tungsten carbide (WC-Co). Int J Adv Manuf Technol 38(11-12):1137-1147
64. Cong WL, Pei ZJ, Mohanty N, Van Vleet E, Treadwell C (2011) Vibration amplitude in rotary ultrasonic machining: a novel measurement method and effects of process variables. J Manuf Sci Eng 133(3):034501

65. Liu J, Chou YK (2007) Cutting tool temperature analysis in heat-pipe assisted composite machining. J Manuf Sci Eng 129(5):902-910

66. Haque S, Bharti PK, Ansari AH (2014) Mechanical and machining properties analysis of Al6061-Cu-reinforced SiCP metal matrix composite. J Miner Mater Charact Eng 2(01):54

67. Taskesen A, Kutukde K (2015) Non-contact measurement and multi-objective analysis of drilling temperature when drilling B4C reinforced aluminum composites. Trans Nonferrous Metals Soc China 25(1):271-283

68. Krishna SAAR, Reddy PR, Reddy PR (2012) Temperature prediction in orthogonal machining of $\mathrm{A} 1 / \mathrm{SICP}$ composites. Int $\mathrm{J}$ Emerg Technol Adv Eng 2:223-229

69. Vinayak K, Aharwal KR (2018) Study and analysis of temperature distribution on AISiC machining on EDM. Int J Sci Eng Manag (IJSEM) 3(5)

70. El-Gallab M, Sklad M (2000) Machining of Al/SiC particulate metal matrix composites part III: comprehensive tool wear models. J Mater Process Technol 101(1-3):10-20

71. Pashnyov VA, Pimenov DY, Erdakov IN, Koltsova MS, Mikolajczyk T, Patra K (2017) Modeling and analysis of temperature distribution in the multilayer metal composite structures in grinding. Int J Adv Manuf Technol 91(9-12):4055-4068

72. Fountas NA, Ntziantzias I, Vaxevanidis NM (2018) Multi-objective optimization of cutting parameters for drilling PA66-GF30 glass fiber reinforced polyamide by employing genetic algorithms. J Manuf Technol Res 10(1/2):1-16

73. Fountas NA, Seretis GV, Manolakos DE, Provatidis CG, Vaxevanidis NM (2018) Multi-objective statistical analysis and optimisation in turning of aluminium matrix particulate composite using genetic algorithms. Int J Mach Mach Mater 20(3):236-251

74. Hakami F, Pramanik A, Basak AK (2017) Tool wear and surface quality of metal matrix composites due to machining: a review. Proc Inst Mech Eng Part B J Eng Manuf 231(5):739-752

75. Akyildiz IF, Su W, Sankarasubramaniam Y, Cayirci E (2002) A survey on sensor networks. IEEE Commun Mag 40(8):102-114

76. Sujith SV, Mulik RS (2020) Thermal history analysis and structureproperty validation of friction stir welded Al-7079-TiC in-situ metal matrix composites. J Alloy Compd 812:152131

77. Lee SJ, Shin SE, Sun Y, Fujii H, Park Y (2018) Friction stir welding of multi-walled carbon nanotubes reinforced Al matrix composites. Mater Charact 145:653-663

78. Patil OM, Khedkar NN, Sachit TS, Singh TP (2018) A review on effect of powder metallurgy process on mechanical and tribological properties of Hybrid nano composites. Mater Today Proc 5(2):5802-5808

79. Nicholls CJ, Boswell B, Davies IJ, Islam MN (2017) Review of machining metal matrix composites. Int J Adv Manuf Technol 90(9-12):2429-2441

Publisher's Note Springer Nature remains neutral with regard to jurisdictional claims in published maps and institutional affiliations. 